\title{
Carpospore release and sporeling development in Gracilaria gracilis (Gracilariales, Rhodophyta) from the southwestern Atlantic coast (Chubut, Argentina)
}

\author{
Karina M. Michetti • Lucas A. Martín • Patricia I. Leonardi
}

Received: 20 December 2012 /Revised and accepted: 25 March 2013/Published online: 21 April 2013

(C) Springer Science+Business Media Dordrecht 2013

\begin{abstract}
The agarophyte Gracilaria gracilis is an economically valuable species exploited in Argentina and the carpospore study is relevant since such spores are used as inoculum for commercial aquaculture. The aims of this work were to describe the carpospore release periodicity and carposporeling development and to evaluate the influence of temperature, irradiance, and day length on carpospore release under laboratory conditions. Desiccation, osmotic shock, and spontaneous discharge were compared as sporulation induction methods and the last one was the best method for improved carpospore release (ANOVA: $F=$ 6.4018, $P<0.05$; least significant difference (LSD) test: $P<$ $0.05)$. The number of carpospores released per cystocarp per day at $13{ }^{\circ} \mathrm{C}$ was significantly greater than at $18{ }^{\circ} \mathrm{C}$ (Student's $t$ test: $t=3.89, P<0.01$ ). Moreover, carpospore release at 12:12-h light/dark (L/D) photoperiod was higher than at 8:16-h L/D photoperiod (Student's $t$ test: $t=2.54, P=$ $0.01)$. No evidence of differences in the number of carpospores per cystocarp per day between high, medium, and low irradiance was recognized (ANOVA: $F=0.82, P>0.25$ ). Sporulation time course analysis showed a peak during the first week with a total carpospore release at the end of the sixth week of about 2,000 carpospores cystocarp ${ }^{-1}$ day $^{-1}$. Carpospore germination and sporeling development were in agreement with the description for other Gracilaria species. This is the first work on carpospore release and germination
\end{abstract}

K. M. Michetti $(\bowtie) \cdot$ L. A. Martín · P. I. Leonardi Laboratorio de Estudios Básicos y Biotecnológicos en Algas y Hongos, Centro de Recursos Naturales Renovables de la Zona Semiárida (CERZOS), CONICET, Camino La Carrindanga, Km 7 , 8000 Bahía Blanca, Argentina

e-mail: michetti@uns.edu.ar

K. M. Michetti • L. A. Martín · P. I. Leonardi Laboratorio de Ficología y Micología, Departamento de Biología, Bioquímica y Farmacia, Universidad Nacional del Sur, 8000 Bahía Blanca, Argentina for an Argentinian strain of G. gracilis and the results could be of interest for further commercial spore culture.

Keywords Carpospores · Germination · Gracilaria gracilis $\cdot$ Sporeling development $\cdot$ Sporulation

\section{Introduction}

Gracilaria species have a significant economic value as a raw material to agar industries and they are exploited taking advantage of their high growth rate and vegetative propagation feasibility (Kain and Destombe 1995). Increased market demand has led to an overharvest of natural beds and consequently to the development of several cultivation methods (Mantri et al. 2009). Gracilaria spp. are cultivated on large and medium scale (Choi et al. 2006; Polifrone et al. 2006).

In commercial cultures sustained by vegetative propagation techniques, productivity declines after $2-3$ years due to thalli aging or intensive harvest (Buschman et al. 1995). Artificial vegetative propagation is unprofitable and demanding because it requires lots of algal material (Jayasankar and Varghese 2002). In contrast, the use of spores as starting material (spore culture) is an efficient technique of propagation that is considered for commercial cultures (Alveal et al. 1997). Tetraspores or carpospores can be used as inoculum. However, the latter is preferred because they are diploid and more vigorous (Mantri et al. 2009); moreover, they come from cystocarps which are easily recognizable to the naked eye on female gametophytes (Glenn et al. 1996).

In Argentina, Gracilaria gracilis (Stackhouse) Steentoft, Irvine and Farnham grows exclusively in Chubut Province (Boraso de Zaixo 1983) where Bahía Bustamante bed is the most important due to its biomass and extension (Martín et al. 2011). For five decades, G. gracilis has been exploited as a source of agar from wave-cast drift material. Despite this 
sustainable procedure, a remarkable depletion of natural resources has been observed since the 1980s (Boraso de Zaixso et al. 2006). Regarding G. gracilis culture, there have been few attempts of cultivation by vegetative propagation (Casas and Piriz 1998) and no spore culture has been performed to date.

Mantri et al. (2009) stated that estimating the spore potential and understanding their early developmental pattern are the most crucial steps in determining the success of sporebased cultivation method. Therefore, basic information about both species' reproductive biology and sporulation conditions is essential. Germination process of carpospores has been described in many species of Gracilaria (Oza and Krishnamurthy 1968; Ogata et al. 1972; Oza 1975; Bird et al. 1977). For some of these species, there is information about the effects of environmental factors on the carpospore release (Yokoya and Oliveira 1993; Orduña-Rojas and Robledo 1999; Guzmán-Urióstegui and Robledo 1999). However, detailed information about the Argentinian G. gracilis strain related to carpospore development and the effects of different abiotic factors on sporulation is lacking.

Aiming at getting baseline information for future spore culture development on the Patagonian coast, the objectives of this study were (1) to evaluate sporulation induction methods and sporulation periodicity; (2) to analyze temperature, irradiance, and day length effects on sporulation; and (3) to track morphological changes of carpospores during early development. Our data obtained at laboratory conditions complements both growth and reproduction results for a natural bed (Martín et al. 2011), and quality, composition, and properties of agar obtained by Rodríguez et al. (2009) and Martín et al. (2012). Our research will contribute to the aquaculture development of $G$. gracilis as a feasible alternative to increase the production of raw material for the agar industry.

\section{Material and methods}

Gracilaria gracilis thalli were collected by scuba diving at 0 - to $8-\mathrm{m}$ depth from a natural bed in Bahía Bustamante $\left(45^{\circ} 08^{\prime} \mathrm{S} 66^{\circ} 32^{\prime} \mathrm{W}\right)$ at Chubut Province, Argentina. The fronds were drained and transported to the laboratory in isolated plastic zip bags under low temperature and darkness in order to avoid carpospore release during transit. Selected mature cystocarpic thalli were cleaned of adhering epiphytes and dirt under a stereoscopic light microscope Leica EZ4. Then, they were rinsed thoroughly in sterile seawater.

For all assays, rinsed thalli were excised into pieces with a sterile surgical blade. Fragments with 24 mature cystocarps of uniform size were placed on a 15-mesh plastic net disk and located in Petri dishes of $5 \mathrm{~cm}$ in diameter containing $10 \mathrm{ml}$ SFC medium (Correa 1990) with germanium dioxide, to suppress diatom growth. Fertile disks were transferred to another Petri dish in order to take carpospore suspension subsamples. For each replicate, three subsamples of $1 \mathrm{~mL}$ suspension were removed to a $1-\mathrm{mL}$ SedgewickRafter chamber with a Pasteur pipette and counted under a compound light microscope Leica DM 2000. Then, average values from the three counts for each replicate were used to estimate carpospore discharge. Released spores were expressed as carpospores per cystocarp per day. For all experiments, thalli cuts were minimized in order to reduce the negative effect on healthy fragments and the photosynthetic activity.

Carpospore release induction methods

The following three induction methods were employed to stimulate carpospore discharge: (1) spontaneous discharge, where fertile fragments were placed with culture medium and left inside until the carpospores were spontaneously discharged; (2) osmotic shock, where fertile fragments were placed in culture medium with high salinity $(60 \%)$ for $30 \mathrm{~min}$ and returned to a medium with normal salinity (34 $\%$ ); and (3) partial desiccation, where fertile fragments were dried at room temperature for $1 \mathrm{~h}$ in the dark and then returned to culture medium. All fragments were kept in a culture chamber at $13 \pm 1{ }^{\circ} \mathrm{C}$ with a $12: 12$-h light/dark photoperiod and an intensity of $30 \mu \mathrm{mol}$ photons $\mathrm{m}^{-2} \mathrm{~s}^{-1}(n=7$, where $n$ is the number of replicates for each treatment). Fertile thalli were collected in early autumn and carpospore release was examined at daily intervals for 4 days, with a daily medium replenish.

Temperature, day length, and irradiance effects on carpospore release

Temperature treatments were performed at $13 \pm 1$ and $18 \pm$ $1{ }^{\circ} \mathrm{C}$ at an irradiance of $30 \mu \mathrm{mol}$ photons $\mathrm{m}^{-2} \mathrm{~s}^{-1}$ provided by daylight fluorescent lamps (L18 W/765; OSRAM, China) and at 12:12-h light/dark (L/D) photoperiod. Fertile thalli were collected in early autumn and output was determined every day for 5 days $(n=10)$.

Day length treatments were performed at 12:12and 8:16-h L/D photoperiods at $13 \pm 1{ }^{\circ} \mathrm{C}$ and $30 \mu \mathrm{mol}$ photons $\mathrm{m}^{-2} \mathrm{~s}^{-1}$. Fertile thalli were collected in winter and output was measured every day for 5 days $(n=5)$.

Irradiance treatments were performed at 60,30 , and $10 \mu \mathrm{mol}$ photons $\mathrm{m}^{-2} \mathrm{~s}^{-1}$ (high, medium, and low irradiance, respectively) at 12:12-h L/D photoperiod and $13 \pm$ $1{ }^{\circ} \mathrm{C}$. Fertile thalli were collected in late autumn and output was measured every day for 9 days $(n=4)$.

Photon flux densities were measured using a LI-COR Underwater Quantum Sensor LI 192 SB. 
Carpospore release periodicity

As female gametophytes bearing cystocarps were present all year, with a maximum in summer and autumn (Martín et al. 2011), the carpospore appearance sequence was evaluated in two seasons with a different behavior: winter and early autumn. Fragments were kept in a culture chamber at a temperature of $13 \pm 1{ }^{\circ} \mathrm{C}$, a $\mathrm{L} / \mathrm{D}$ photoperiod of $12: 12 \mathrm{~h}$, and an intensity of $30 \mu \mathrm{mol}$ photons $\mathrm{m}^{-2} \mathrm{~s}^{-1}$. Carpospore counts were done at 48 -h periods, for 22 days in winter $(n=$ $16)$ and 38 days in autumn $(n=7)$.

Development of juvenile carposporelings

Released carpospores from thalli with 120 mature cystocarps were cultivated in Petri dishes of $10 \mathrm{~cm}$ in diameter with $20 \mathrm{ml}$ culture medium at a temperature of $13 \pm 1^{\circ} \mathrm{C}$, a L/D photoperiod of 12:12 h, and $30 \mu \mathrm{mol}$ photons $\mathrm{m}^{-2} \mathrm{~s}^{-1}$ and settled on immersed cover slips. Nascent carpospore diameter was recorded before undergoing first division $(n=56)$.

Juvenile tetrasporophytic thalli development was registered by examination of immersed cover slips by using stereoscopic and compound light microscopes. The culture medium was replenished once a week and thalli development was measured for 6 months by initial measurements of the basal disk diameter followed by measurements of the length of erect frond.

\section{Statistical analysis}

Results are expressed as mean \pm standard error. Data were subjected to Student's $t$ test and one-way ANOVA with LSD multiple comparison tests. Day length count data were lntransformed and the count data of the carpospore release periodicity were quadratic root-transformed before analysis. Statistical analyses were carried out using InfoStat (Di Rienzo et al. 2011).

\section{Results}

Carpospore release in $G$. gracilis was highly influenced by the induction method used, with a maximum shedding of around 1,000 carpospores cystocarp ${ }^{-1}$ day $^{-1}$. For the three induction methods, differences in the daily carpospore release in $G$. gracilis were statistically significant (ANOVA: $F=6.4018, P<0.05$ ) (Fig. 1). Main differences were observed between spontaneous discharge and the desiccation method (LSD test: $P<0.05$ ), but no significant differences were observed between spontaneous discharge and osmotic shock. Although carpospore release with osmotic shock was higher than the one obtained with desiccation, these differences were not significant $(P>0.05)$.

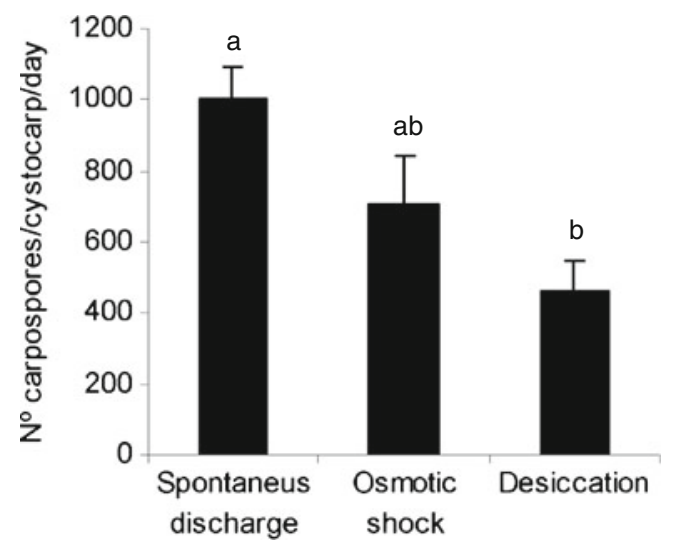

Fig. 1 Number of carpospores released per cystocarp per day in $G$. gracilis as a function of induction method. Different letters represent significant differences. Standard error is indicated

Temperature had a marked effect on sporulation. The number of carpospores released per cystocarp per day showed highly significant differences at $13{ }^{\circ} \mathrm{C}(699.2 \pm$ 210.8) compared with $18{ }^{\circ} \mathrm{C}(408.7 \pm 123.2)$ (Student's $t$ test: $t=3.89, P<0.01)$.

The number of carpospores released per cystocarp per day showed highly significant differences at 12:12-h (44.8 \pm 20.0) and 8:16-h L/D photoperiods (14.4 \pm 6.4$)$ (Student's $t$ test: $t=2.54, P=0.01$ ).

No evidence of irradiance effect on carpospore output was found. Differences in the number of carpospores per cystocarp per day between high $(88.1 \pm 22.8)$, medium $(129.1 \pm 22.2)$, and low irradiance $(114.3 \pm 23.7)$ were not significant (ANOVA: $F=0.82, P>0.25$ ).

\section{Carpospore release periodicity}

Sporulation of about 80-800 carpospores cystocarp ${ }^{-1}$ day $^{-1}$ was observed in a period of 6 weeks during autumn. The sporulation sequence was registered and highly significant differences were found between weeks (ANOVA: $F=25.11$, $P<0.0001)$. Significant differences were observed between the first and second weeks and between the third and sixth weeks (LSD test: $P<0.05$ ) (Fig. 2a). The highest and lowest mean outputs appeared in the first and sixth weeks, respectively. In the first week, highly significant differences were found between days (ANOVA: $F=5.2$, $P<0.01)$. A posteriori LSD test showed that the carpospore release at days 1 and 7 was significantly higher $(P<0.05)$ than those at days 4 and 5, while there were no differences between days 2, 3, and 4 (Fig. 2b). The total carpospore release per cystocarp at the end of the sixth week was $2,036 \pm 122$.

In winter, sporulation was greatly diminished and it could only be measured during the first 3 weeks because that release was too low to be evaluated afterwards. The quantity 
a

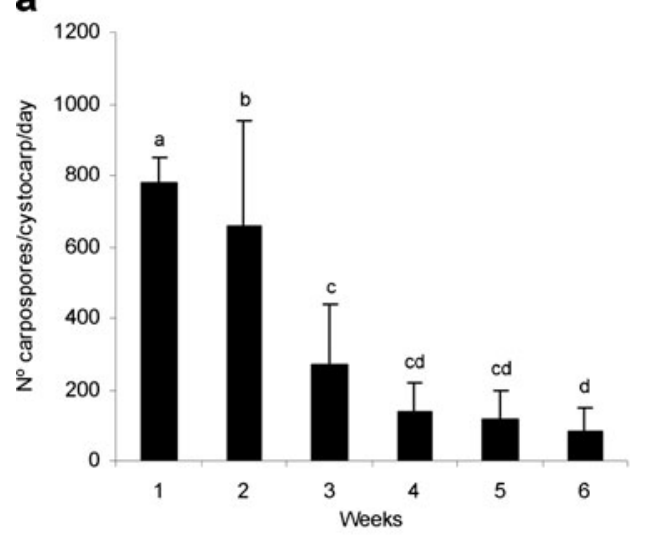

b

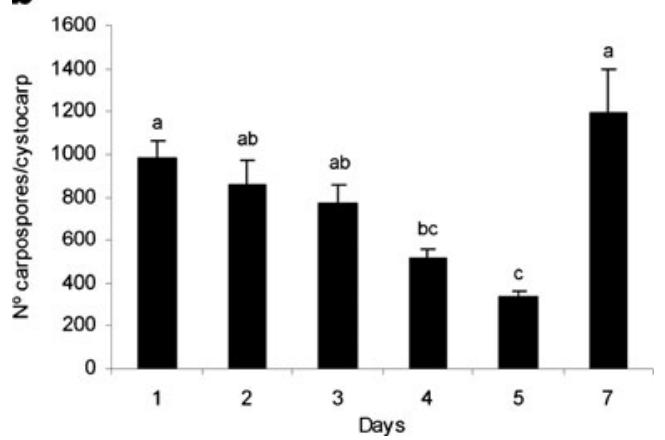

Fig. 2 Carpospore release time course in G. gracilis during autumn. a Number of carpospores released per cystocarp per day as a function of weeks. b Number of carpospores released per cystocarp during the first week. Different letters represent significant differences. Standard error is indicated

of carpospores released ranged from 2 to 16 per cystocarp per day. There were highly significant differences between weeks (ANOVA: $F=6.54, P<0.01$ ) with the minimum discharge on the third week and without any differences between the first and second weeks (LSD test: $P>0.05$ ) (Fig. 3a). Daily carpospore release analysis revealed highly significant differences (ANOVA: $F=5.71, P<0.0001$ ), with two peaks of similar magnitude on day 5 (Fig. 3b). For all assays, carpospores were released during the first $24 \mathrm{~h}$, except during winter when sporulation was delayed between 4 and 7 days.

Carpospore release, germination pattern, and early tetrasporophyte development

The carpospores were spherical, densely pigmented, $34.8 \pm$ $4.6 \mu \mathrm{m}$ in diameter with a minimum of $25 \mu \mathrm{m}$ and a maximum of $50 \mu \mathrm{m}(n=56)$ (Fig. $4 \mathrm{a})$. The settled carpospores underwent germination immediately without any resting period. The first division took place in a median plane forming two equal halves (Fig. 4b). Within 2-3 days, each cell divided perpendicularly with respect to the first division, without volume expansion, originating three and

\section{a}

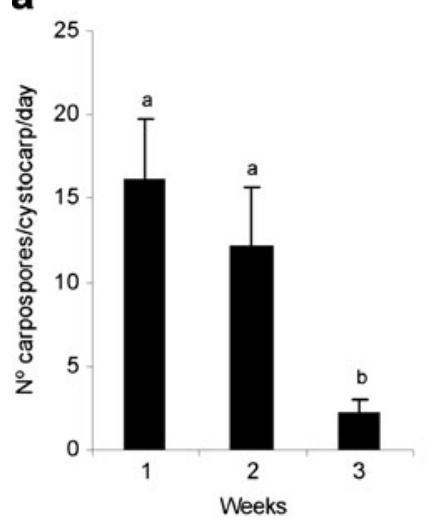

b

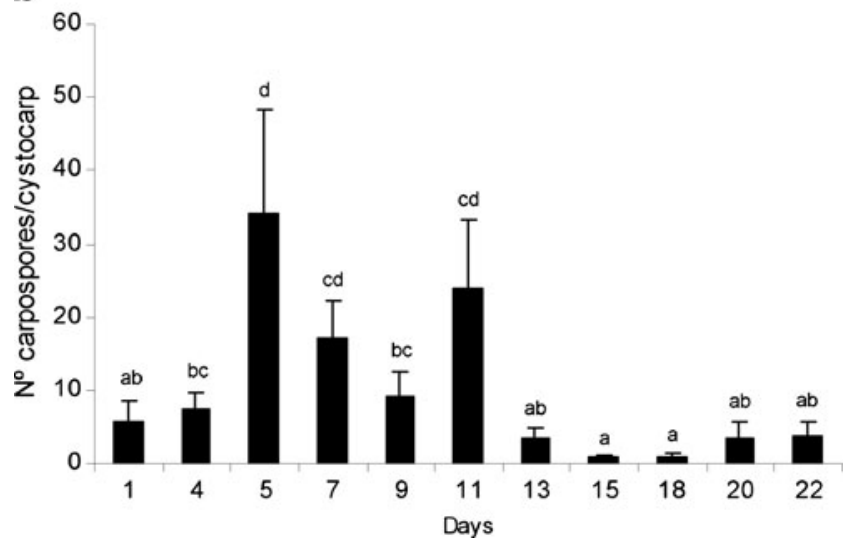

Fig. 3 Carpospore release time course in G. gracilis during winter. a Number of carpospores released per cystocarp per day as a function of weeks. b Daily analysis of the number of carpospores released per cystocarp. Different letters represent significant differences. Standard error is indicated

four cellular stages (Fig. 4c, d). Within 4-6 days, several divisions occurred originating a multicellular disk that kept the carpospore diameter (Fig. 4e). On the second week, multicellular disks attained a diameter of $81.0 \pm 9.7 \mu \mathrm{m}$ $(n=25)$ (Fig. 4f). Further periclinal divisions led to the formation of a hemispherical mass or dome-shaped structure, which was achieved on the third week (Fig. 4g). Furthermore, differentiated rhizoids were observed in this stage (Fig. 4h). The dome center gradually became arched to establish an apical polarity (Fig. 5a) with the formation of an erect frond of $174.8 \pm 58.7 \mu \mathrm{m}(n=27)$ by the end of the first month (Fig. 5b). The erect cylindrical frond attained a length of $1.4 \pm 0.4 \mathrm{~mm}$ (Fig. $5 \mathrm{c}$ ) by the second month $(n=30)$. The fronds reached a size of $14.2 \pm 1.8 \mathrm{~mm}$ with apical branches (Fig. 5d) within 6 months of culture $(n=15)$.

Coalescence of adjacent prostrate disks was observed up to nine disks, but not all disks produced erect shoots (Fig. 5e). No morphological difference appeared in the development of erect germlings from single or coalesced disks. 
Fig. 4 Carpospore germination and carposporeling

development in G. gracilis. a Freshly released carpospores. b Bicellular stage, $24 \mathrm{~h}$ old. c, d Tri- and tetracellular stages, respectively, 2-3 days old. e Multicellular disk, 4-6 days old. f Early formation of primary prostrate disk, 2 weeks old. g Dome stage, 3 weeks old. h Lateral view of a disk showing a rhizoid (arrow). Scale bars: a-e $20 \mu \mathrm{m}, \mathbf{f}-\mathbf{h}$ $40 \mu \mathrm{m}$
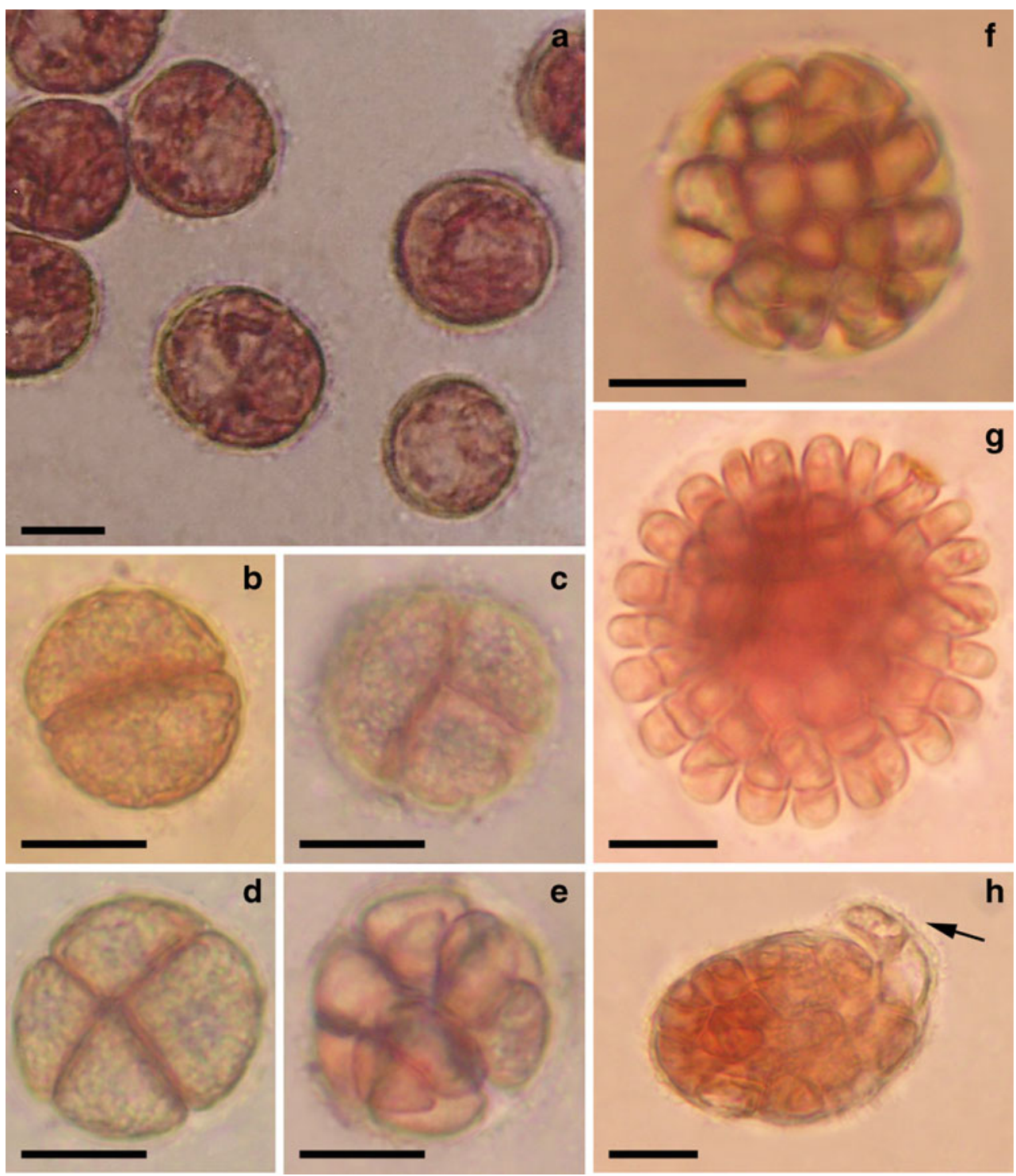

\section{Discussion}

From the foregoing results, it is observed that under laboratory conditions, the release of G. gracilis carpospores was sensitive to temperature and day length. Furthermore, this species presented a spore potential of about 1,000 carpospores cystocarp ${ }^{-1}$ day $^{-1}$ with an extended discharge during the first 2 weeks. The carpospore induction method had no significant effect on carpospore shedding in G. gracilis; thus, the spontaneous discharge was the best option.

Sporulation was tested within the summer and autumn temperature ranges as indicated by Martín et al. (2011) in Bahía Bustamante $\left(18\right.$ to $13{ }^{\circ} \mathrm{C}$ ) when G. gracilis expressed the maximum proportion of cystocarpic thalli, observing the best response at $13{ }^{\circ} \mathrm{C}$. However, in other temperate species as Gracilaria pacifica, the highest release occurred at a higher temperature within the range, i.e., $21{ }^{\circ} \mathrm{C}$ for the NW coast of Mexico (Garza-Sánchez et al. 2000).
Even though sporulation in both day length conditions was particularly low due to poor fertility in winter, lower sporulation was registered under the 8:16-h L/D photoperiod condition. For two species of Gelidiales and other red algae, a short day length condition determined the lower number of spores shed (Umamaheswara Rao and Kaliaperumal 1983). On the contrary, in Gracilaria cornea, short day conditions produce a higher number of carpospores (Guzmán-Urióstegui and Robledo 1999). According to Santelices (1990), it remains unclear how light or darkness might affect the potential for carpospore release.

No irradiance effect was detected on carpospore release in G. gracilis, while in other species, such as Gracilaria foliifera, low irradiance increases carpospore release (Friedlander and Dawes 1984). Furthermore, Santelices (1990) in his review on seaweed reproduction points out that low illumination conditions seem to increase propagule output. 
Fig. 5 Early development of tetrasporophytic thalli in $G$. gracilis. a Apical shoot growth (arrow). b, c Erect cylindrical thalli after 1- and 2-month culture, respectively. d Juvenile tetrasporophytes of 6 months old. e Coalescence of prostrate disks. Scale bars: a, b $50 \mu \mathrm{m}, \mathbf{c}$ $0.25 \mathrm{~mm}, \mathbf{d} 25 \mathrm{~mm}$, e $1 \mathrm{~mm}$

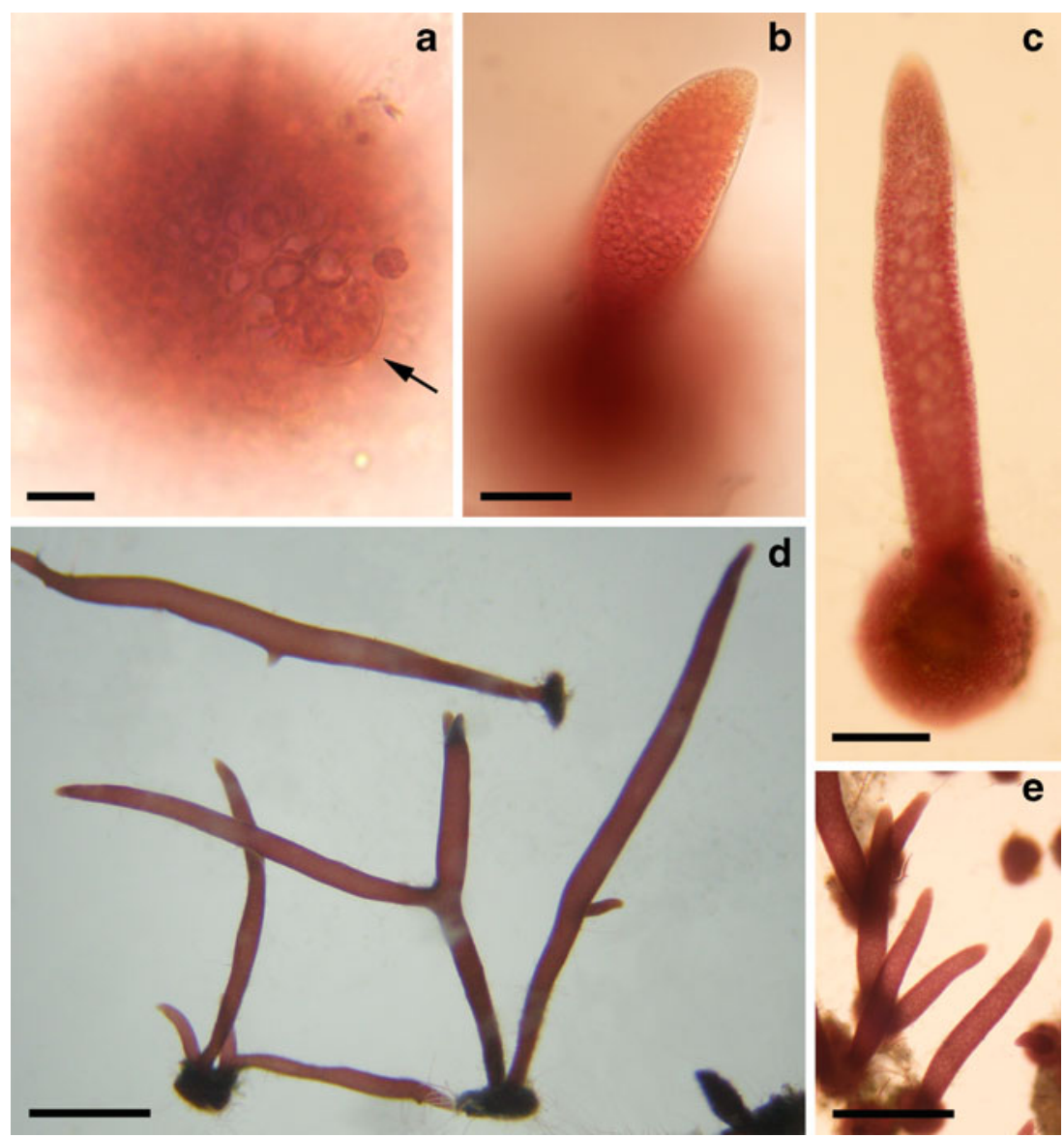

Our results seem to indicate that carpospore release in $G$. gracilis is mainly affected by temperature and photoperiod, whereas induction method and irradiance do not have a significant effect. A similar result was observed in $G$. cornea, a species reported for the northwestern Atlantic (Guzmán-Urióstegui and Robledo 1999; Orduña-Rojas and Robledo 1999).

Carpospore release in autumn was observed for six weeks in G. gracilis. Seventy percent of the carpospores were liberated within the first 2 weeks and a pronounced decreasing trend occurred towards the last week. In most of the studied Gracilaria species, the maximum carpospore discharge occurred within the first 3 days followed by a rapid decline in daily output (Kain and Destombe 1995; Guzmán-Urióstegui and Robledo 1999; Garza-Sánchez et al. 2000; Mantri et al. 2009). According to Guzmán-Urióstegui and Robledo (1999), these differences could be related to algal origin (temperate or tropical) with an extended shedding for temperate species. This seems to be the case for $G$. gracilis from the southwestern Atlantic coast where the maximum carpospore release occurred on day 7. Furthermore, a delayed peak in carpospore discharge was also observed in G. dura (Mantri et al. 2009).

In G. gracilis, daily peaks in both autumn (days 1 and 7) and winter (days 5 and 11) have not been statistically recognized. However, we can envisage that a trend may exist and that this similar carpospore discharge pattern with two peaks in a period of 6 days might indicate a certain periodicity in carpospore release. In fact, in Gracilaria verrucosa (= G. gracilis), Lefebvre et al. (1987) observed a rhythmic carpospore liberation for about a month. In addition, a discharge at intervals of 4-5 days was reported by Oza and Krishnamurthy (1968) for the same species, by Rama Rao and Thomas (1974) for Gracilaria edulis, and by Joseph Mohan and Krishnamurthy (1977) for Gracilaria corticata.

In comparison with autumn, a diminished reproductive activity was detected in $G$. gracilis in winter assays with a greatly reduced carpospore count. Besides, a delayed carpospore release became evident with a retarded first peak on day 5. As a matter of fact, Boraso de Zaixo (1987) noted that seasonality imposes limits to the reproductive activity in $G$. verrucosa $(=G$. gracilis $)$ with a maximum of cystocarpic thalli in summer and autumn.

The maximum carpospore release per cystocarp per day in G. gracilis $(1,194)$ was higher than the one reported in Gracilaria dura (808) (Mantri et al. 2009), but it was lower than that registered in $G$. corticata $(4,911)$ (Umamaheswara Rao 1976) and G. cornea $(8,000$ to 11,000$)$ (GuzmánUrióstegui and Robledo 1999). In general, up to 6,000 carpospores are obtainable from one mature cystocarp of Gracilaria (Destombe 1987). The total number of carpospores per 
cystocarp in $G$. gracilis $(2,036)$ was within the range proposed by Infante and Candia (1988) for Gracilaria chilensis (as $G$. verrucosa) (60 to 2,900) and Orduña-Rojas and Robledo (1999) for $G$. cornea (2,500), while it was higher than the number measured for G. corticata (200 to 250) by Oza (1975).

In this study, the maximum carpospore release was observed in early autumn when the natural population of $G$. gracilis recorded high frequency of cystocarpic thalli (Martín et al. 2011). Similarly, in other species, the peak carpospore output occurs during the maximum growth period (Kaliaperumal et al. 1986). Kain and Destombe (1995) stated that at high latitudes, reproduction peaks in Gracilaria spp. are evident in late summer.

Taking into consideration the spore output for all assays and focusing on the collection season of fertile thalli, we determine maximum sporulation in early autumn, a sharp output decrease in late autumn, and a nearly insignificant release in winter with a sporulation lower than $5 \%$ of that observed in autumn.

Carpospore size for G. gracilis is similar to that of other temperate species such as G. chilensis (Yokoya and Oliveira 1993), whereas in tropical species, carpospores are smaller (Guzmán-Urióstegui and Robledo 1999; Orduña-Rojas and Robledo 1999).

The carpospore germination in G. gracilis belongs to Dumontia type and is in agreement with the carpospore germination process described for other Gracilaria species (Yokoya and Oliveira 1993; Orduña-Rojas and Robledo 1999). According to Murray and Dixon (1992), this unipolar germination pattern favors firm attachment prior to erect shoot development. Knowledge about the developmental stages of carpospore germination is relevant for further Gracilaria farming based on spore culture.

According to Jones (1956), sporelings in $G$. verrucosa $(=G$. gracilis) could not be recognized as individual coalesced disks, whereas in this investigation, we have always distinguished individual sporelings. In agreement with Oliveira and Plastino (1984) and Bird et al. (1977), the erect fronds for Gracilaria spp. were equally produced from disks which originated from isolated carpospores as well as from those coming from coalescing sporelings in G. gracilis. However, not all the coalesced prostrate disks originated from erect shoots; such a phenomenon was observed by Jones (1956) for G. verrucosa and by Santelices et al. (2004) for several red algae, who stated that it might depend on disk diameter just before coalescence. After 2 months of culturing, carposporelings of $G$. gracilis reached around $1.5 \mathrm{~mm}$. Sizes ranging from 0.7 to $1.5 \mathrm{~mm}$ have been suggested as the desirable length for outplanting in the sea for G. chilensis (Alveal et al. 1997).

This is the first study of an Argentinian strain of $G$. gracilis on carpospore release and germination. Even though only a few factors affecting carpospore release were investigated, these results are interesting for the exploration of its potential application in artificial sporeling nursery for further spore culture at pilot scale. In this sense, the following should be considered: (1) early autumn seems to be an appropriate season for the beginning of spore cultures as supported by field observations (Martín et al. 2011), (2) no induction treatments are apparently necessary in order to stimulate carpospore discharge, and (3) cultures of fertile thalli at $13{ }^{\circ} \mathrm{C}$, 12:12-h L/D photoperiod, and $30 \mu \mathrm{mol}$ photons $\mathrm{m}^{-2} \mathrm{~s}^{-1}$ during 1 or 2 weeks would guarantee a reasonable initial carpospore output. Besides considering the prolonged and massive discharge of carpospores during the first 2 weeks $(70 \%$ of total amount), it is recommended to maintain fertile thalli over the substrate to be inoculated at least for 1 week.

The implementation of repopulation methods through spore culture in G. gracilis is desirable in order to increase the standing stock and genetic variability in natural beds (Martín et al. 2011). Consequently, further works in this line will be of pivotal importance to the seedling production of this agarophyte species.

Acknowledgments This study was supported by Consejo Nacional de Investigaciones Científicas y Técnicas (CONICET) under grants PIP 5045 and PIP 11220080100234 and also by Agencia Nacional Argentina para la Promoción Científica y Tecnológica under grant BID 1728/OCAR-PICT 632. We are thankful to K. Alveal for training K. Michetti in the laboratory experiences of carpospore release and germination. We would also like to thank Soriano S.A. for their logistic assistance during our work in the field. KMM and PIL are research members of CONICET.

\section{References}

Alveal K, Romo H, Werlinger C, Oliveira EC (1997) Mass cultivation of the agar-producing alga Gracilaria chilensis (Rhodophyta) from spores. Aquaculture 148:77-83

Bird NL, McLachlan J, Grund D (1977) Studies on Gracilaria. 5. In vitro life history of Gracilaria sp. from the maritime provinces. Can J Bot 55:1282-1290

Boraso de Zaixo AL (1983) Ecología de Gracilaria verrucosa (Hudson) Papenfus en poblaciones de la provincia de Chubut (Argentina). $\mathrm{PhD}$ Thesis, Universidad Nacional de Buenos Aires, Argentina

Boraso de Zaixo AL (1987) Gracilaria verrucosa in Golfo Nuevo, Chubut, Argentina. Biological parameters and environmental factors. Hydrobiologia 151/152:239-244

Boraso de Zaixso AL, Ciancia M, Cerezo A (2006) Seaweed resources of Argentina. In: Critchley AT, Ohno M, Largo DB (eds) World seaweed resources an authoritative reference system. ETI, Univ. Amsterdam, $26 \mathrm{pp}$

Buschman AH, Westermeier R, Retamales C (1995) Cultivation of Gracilaria on the sea-bottom in the southern Chile: a review. J Appl Phycol 7:291-301

Casas GN, Piriz ML (1998) Cultivo experimental de la agarífera Gracilaria gracilis (Gracilariales, Rhodophyta) en Golfo Nuevo, Argentina. Naturalia Patagonica 6:51-69

Choi HG, Kim YS, Kim JH, Lee SJ, Park EJ, Ryu J, Nam KW (2006) Effects of temperature and salinity on the growth of Gracilaria verrucosa and G. chorda with the potential for mariculture in Korea. J Appl Phycol 18:269-277 
Correa JA (1990) Pigmented algal endophytes of Chondrus crispus Stackhouse: host specificity, fine structure and effects on host performance in infections by Acrochaete operculata Correa and Nielsen. PhD Thesis, Dalhousie University, Canada

Destombe C (1987) Biologie des populations de'l algue rouge Gracilaria verrucosa Hudson (Papenfuss) (Gigartinales), intérêt et implication en aquaculture. $\mathrm{PhD}$ thesis, Université des Sciences et Techniques de Lille Flandres-Artois, Lille, France

Di Rienzo JA, Casanoves F, Balzarini MG, Gonzalez L, Tablada M, Robledo CW (2011) InfoStat versión 2011 Grupo InfoStat, FCA, Universidad Nacional de Córdoba, Argentina. http://www.infostat.com.ar

Friedlander M, Dawes CJ (1984) Studies on spore release and sporeling growth from carpospores of Gracilaria foliifera (Forsskål) Børgesen var. angustissima (Harvey) Taylor. I. Growth responses. Aquat Bot 19:221-232

Garza-Sánchez F, Zertuche-González JA, Chapman DJ (2000) Effect of temperature and irradiance on the release, attachment and survival of spores of Gracilaria pacifica Abbott (Rhodophyta). Bot Mar 43:205-212

Glenn EP, Moore D, Fitzsimmons K, Azevedo C (1996) Spore culture of the edible red seaweed, Gracilaria parvispora (Rhodophyta). Aquaculture 142:59-74

Guzmán-Urióstegui A, Robledo D (1999) Factors affecting sporulation of Gracilaria cornea (Gracilariales, Rhodophyta) carposporophytes from Yucatán, México. Hydrobiologia 398/399:285-290

Infante R, Candia A (1988) Cultivation of Gracilaria verrucosa (Hudson) Papenfuss and Iridaea ciliata Kutzing (Rhodophyta, Gigartinaceae), "in vitro". Induced shedding and carpospore colonization on different substrata. Gayana Bot 45:297-304

Jayasankar R, Varghese S (2002) Cultivation of marine red algae Gracilaria edulis (Gigartinales, Rhodophyta) from spores. Indian J Mar Sci 31:75-77

Jones WE (1956) Effect of spore coalescence on the early development of Gracilaria verrucosa (Hudson) Papenfuss. Nature 178:426-427

Joseph Mohan M, Krishnamurthy V (1977) Studies on the shedding of carpospores in Gracilaria corticata. J Ag. Seaweed Res Util 2:1-8

Kain JM, Destombe C (1995) A review of the life history, reproduction and phenology of Gracilaria. J Appl Phycol 7:269-281

Kaliaperumal N, Chennubhotla VSK, Kalimuthu S, Ramalingam JR (1986) Growth, phenology and spore shedding in Gracilaria arcuata var. arcuata (Zanardini) Umamaheswara Rao \& G. corticata var. cylindrica (J. Agardh) Umamaheswara Rao (Rhodophyta). Ind J Mar Sci 15:107-110

Lefebvre CA, Destombe C, Godin J (1987) Le fonctionnement du carposporophyte de Gracilaria verrucosa et ses répercussions sur la stratégie de reproduction. Cryptogamie Algol 8:113-126

Mantri VA, Thakur MC, Kumar M, Reddy CRK, Jha B (2009) The carpospore culture of industrially important red alga Gracilaria dura (Gracilariales, Rhodophyta). Aquaculture 297:85-90
Martín L, Boraso de Zaixo A, Leonardi PI (2011) Biomass variation and reproductive phenology of Gracilaria gracilis in a patagonic natural bed (Chubut, Argentina). J Appl Phycol 23:643-654

Martín LA, Rodríguez MC, Matulewicz MC, Fissore E, Gerschenson LN, Leonardi PI (2012) Seasonal variation in agar composition and properties from Gracilaria gracilis (Gracilariales, Rhodophyta) of the Patagonian coast of Argentina. Phycol Res (in press)

Murray SN, Dixon PS (1992) The Rhodophyta: some aspects of their biology. III. Oceanogr Mar Biol Ann Rev 30:1-148

Ogata E, Matsui T, Nakamura H (1972) The life cycle of Gracilaria verrucosa (Rhodophyceae, Gigartinales) in vitro. Phycologia 11:75-80

Oliveira EC, Plastino EM (1984) The life history of some species of Gracilaria (Rhodophyta) from Brasil. Jpn J Phycol 32:1-6

Orduña-Rojas J, Robledo D (1999) Effect of irradiance and temperature on the release and growth of carpospores from Gracilaria cornea J. Agardh (Gracilariales, Rhodophyta). Bot Mar 42:315319

Oza RM (1975) Studies on Indian Gracilaria. 1. Carpospore and tetraspore germination and early stages of development in Gracilaria corticata. J Ag Bot Mar 18:199-201

Oza RM, Krishnamurthy V (1968) Studies on carposporic rhythm of Gracilaria verrucosa (Huds) Papenf. Bot Mar 11:118-121

Polifrone M, De Masi F, Gargiulo GM (2006) Alternative pathways in the life history of Gracilaria gracilis (Gracilariales, Rhodophyta) from north-eastern Sicily (Italy). Aquaculture 261:1003-1013

Rama Rao K, Thomas PC (1974) Shedding of carpospores in Gracilaria edulis (Gmel.) Silva. Phykos 13:54-59

Rodríguez MC, Matulewicz MC, Noseda MD, Ducatti DR, Leonardi PI (2009) Agar from Gracilaria gracilis (Gracilariales, Rhodophyta) of the Patagonic coast of Argentina - content, structure and physical properties. Biores Technol 100:1435-1441

Santelices B (1990) Patterns of reproduction, dispersal and recruitment in seaweeds. Oceanogr Mar Biol Annu Rev 28:177-276

Santelices B, Hormazabal M, Correa J, Flores V (2004) The fate of overgrown germlings in coalescing Rhodophyta. Phycologia 43:346-352

Umamaheswara Rao M (1976) Spore liberation in Gracilaria corticata J. Agardh growing at Mandapam. J Exp Mar Biol Ecol 21:91-98

Umamaheswara Rao M, Kaliaperumal N (1983) Effects of environmental factors on the liberation of spores from some red algae of Visakhapatnam coast. J Exp Mar Biol Ecol 70:45-53

Yokoya NS, Oliveira EC (1993) Effects of temperature and salinity on spore germination and sporeling development in South American agarophytes (Rhodophyta). Jpn J Phycol 41:283-293 